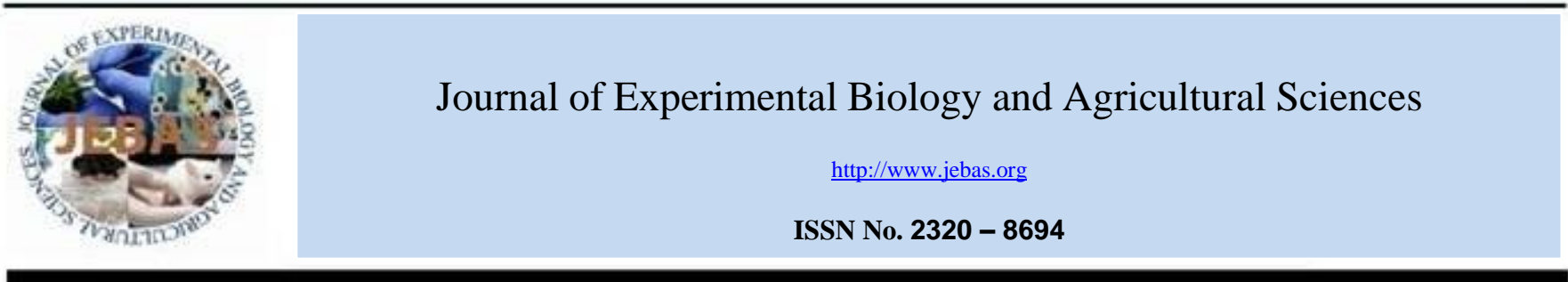

\title{
DOES PLAYING LOCATION-BASED AUGMENTED REALITY GAME INCREASES THE LEVEL OF PHYSICAL ACTIVITY?
}

\author{
Low Ann Gee ${ }^{1}$, Ambusam Subramaniam ${ }^{1 *}$, Sivaguru Muthusamy ${ }^{1,2}$, Rajkumar Krishnan Vasanthi ${ }^{1}$ \\ ${ }^{1}$ Physiotherapy programme, INTI International University, Nilai, Negeri Sembilan, Malaysia \\ ${ }^{2}$ Department of Physical Education \& Health Sciences, Alagappa University, Tamil Nadu, India
}

Received - July 18, 2020; Revision - September 17, 2020; Accepted - January 03, 2021

Available Online - March 25, 2021

DOI: http://dx.doi.org/10.18006/2021.9(Spl-1-GCSGD_2020).S182.S186

\section{KEYWORDS \\ Augmented reality games \\ Pokémon Go \\ Level of physical activity \\ Gamification \\ Location-based}

* Corresponding author

E-mail: ambusam_7@hotmail.com (Ambusam Subramaniam)

Peer review under responsibility of Journal of Experimental Biology and Agricultural Sciences.

Production and Hosting by Horizon Publisher India [HPI] (http://www.horizonpublisherindia.in/).

All rights reserved.

\begin{abstract}
Recently, there are an increasing trend in location-based augmented reality (AR) games that require players to move around physically to acquire the in-game features as well as game bonuses. The introduction of this location-based augmented reality (AR) games, specifically, Pokémon Go, has made the players physically move around to achieve higher levels and indirectly, improves the level of physical activity. Thus, the objective of the current study is to examine the association between the time spent playing location-based AR games specifically Pokémon Go, and the level of physical activity of the players in Malaysia. A self-administered questionnaire was circulated among Pokémon Go players and based on the inclusion and exclusion criteria, 47 players were recruited in the study. Global Physical Activity Questionnaire (GPAQ) was used to identify the level of physical activity. The association between time spent playing Pokémon Go and level of physical activity were examined using the Chi-square test. The results of the current study showed no significant association between days spent playing Pokémon Go and level of physical activity $(\mathrm{p}=.14)$, hours spent playing Pokémon Go and physical activity $(\mathrm{p}=.516)$, or between daily hours spent playing Pokémon Go and daily sedentary time $(p=.283)$. Nevertheless, the mean of the study reported that the physical activity level of the players increased concurrently as the player's game frequency increases. Further studies are required to shed light on how location-based AR games can be implemented as potential strategies to engage an active lifestyle.
\end{abstract}

All the articles published by Journal of Experimental Biology and Agricultural Sciences are licensed under a Creative Commons Attribution-NonCommercial 4.0 International License Based on a work at www.jebas.org.

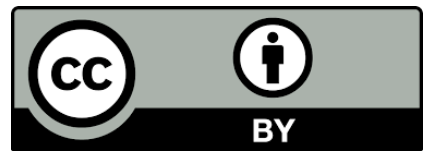




\section{Introduction}

In today's generation, there is a growing concern over the consequences of sedentary lifestyle practice and physical inactivity. Physical activity refers to the involvement of bodily movement that requires the usage of energy in our daily life (WHO, 2020). According to the Global Health Observatory of WHO, the prevalence of physical inactivity among adults aged 18 and above in Malaysia was $38.8 \%$ in the year 2016 while females constitute the majority $(42.8 \%$ ) whereas males were $34.6 \%$ (WHO, 2018)

Moreover, a previous study has reported that campaigns to promote physical activity had only achieved limited success and yielded non-significant results (Leavy et al., 2011). Over the long run, physical inactivity will impact the population with major health repercussions especially non-communicable diseases (NCD) such as cardiovascular disease (CVD), hypertension, diabetes, and others (Zulkepli et al., 2019). Therefore, there is a crucial need of promoting the importance of physical activity among the public health to improve and sustain good health and quality of life.

The recent growth of smart phone obsession and mobile gamification are emerging rapidly among people regardless of their age, gender or status. The increased trends of mobile games are commonly linked with the practice of sedentary lifestyles and lack of physical activity.

However, the introduction of location-based (geolocation) augmented reality games have led to a turn of the tide. Augmented Reality (AR) is a software technology that capable of overlaying a real environment with a virtual $2 \mathrm{D}$ or $3 \mathrm{D}$ computer-generated image (Carlson \& Gagnon, 2017). Location-based AR games use three features of the smart phone: Global Positioning System (GPS) to locate the device's location, the phone's compass to obtain the direction of the player is facing, and lastly, an accelerometer to obtain the orientation of the phone.

A popular example of location-based AR games is Pokémon Go. The game requires players to walk around the neighbourhood to obtain in-game features and bonuses. The players have no point staying at one place as the game's design is to get people moving. The players are required to walk, jog or run around the neighbourhood to catch Pokémons, interact with Pokéstops and PokéGyms to level up faster, and connect with other players. Thus, location-based AR games do the opposite of what mobile games do: to avoid players staying still at one place while playing the game.

Thus, this study was conducted to provide an insight on whether Pokémon Go is associated with the increase in physical activity level after the game was released since the year 2016. The objective of the current study is to examine the association between the time spent playing location-based AR games and the level of physical activity of the players.

\section{Materials and Methods}

\subsection{Subjects}

A cross sectional study was conducted to examine the association between the time spent playing location-based AR games and the level of physical activity of the players. Using convenience sampling, Pokémon Go Groups of different states on Facebook and WhatsApp were identified and the online questionnaires were distributed within the group. Questionnaires were also distributed to Pokémon Go Players on Pokémon Go's Community day at Pokémon Go active playing locations. The sample size of the current study was 84 participants.

Nevertheless, the total subjects recruited yielded 47 players based on the predefined inclusion and exclusion criteria. The participants in the current study were between 18 to 40 years old and both male and female were recruited in the study. Players that drive to play the game, already physically active before playing Pokémon Go, already vigorously active at work, or uses "GPS spoofing apps" were excluded from the study.

In the beginning, the author has informed the study procedure to the players and written informed consent was attained before the study. The Research Ethics Committee of INTI International University, Malaysia permitted to conduct the study (FHLS/RAC/JUL/12)

\subsection{Procedure}

The players were given a demographic questionnaire that includes age, gender, years of playing Pokémon Go, and time spent playing per hours/day and per days/week. The questionnaire was pre-tested by peers who played Pokémon Go to identify technical errors and misapprehension of vocabulary in the questionnaire.

Also, the Global Physical Activity Questionnaire (GPAQ) version 2.0 was used in the current study. The GPAQ V. 2.0 provides information in the physical activity level based on 4 domains "Work", "Transport", "Recreational Activity" and "Sedentary Behavior" in terms of "frequency" quantified as days per week and "duration" quantified as hours and minutes per day (Mum et al., 2017).

The data collected in GPAQ were analysed and expressed as Total Physical Activity in minutes per week or METs (Metabolic Equivalents) according to the physical activity level. The METs value can be categorized based on the following category; Inactivity with 1 MET, moderate and vigorous represented with 4 and 8 METs respectively (Herrmann et al., 2013).

\subsection{Statistical Analysis}

Data were analyzed using Statistical Software Package SPSS (Version 26.0, Chicago, IL, USA). Shapiro-Wilk test was used to 
analyze the data and normal distribution was reported. Descriptive analysis were used to analyze the demographic details such as the age, gender, years started playing Pokémon Go as well as the time spent playing per hours/day and per days/week.

The data were not normally distributed, thus, the median score has been reported. Chi-square analyses were employed to analyze the days spent playing Pokémon Go and level of physical activity; days spent playing Pokémon Go and sedentary time with p-value of $<0.05$.

\section{Results}

3.1 Demographics details of the subjects

Forty-seven participants were recruited in the current study. Most of the players were aged between $21-30$ years $(55.3 \%)$, among these majority are male (61.7\%) and started playing Pokémon Go in the year $2016(85.1 \%)$. The majority of the players $(70.2 \%)$ spent 6 to 7 days in a week playing Pokémon Go and spent 1 to 4 hours a day (59.6\%) playing Pokémon Go. Table 1 represents the demographic details of the players.

Table 1 Demographic details of the participants

\begin{tabular}{|c|c|c|}
\hline Demographic variable & Number (n) & Percentage (\%) \\
\hline $\begin{array}{r}18-20 \\
21-30 \\
31-40\end{array}$ & $\begin{array}{c}4 \\
26 \\
17\end{array}$ & $\begin{array}{c}8.5 \\
55.3 \\
36.2\end{array}$ \\
\hline \multicolumn{3}{|l|}{ Gender } \\
\hline Male & 29 & 61.7 \\
\hline Female & 18 & 38.3 \\
\hline \multicolumn{3}{|l|}{ Number of the year started playing Pokémon Go } \\
\hline 4 years & 40 & 85.1 \\
\hline 3 years & 2 & 4.3 \\
\hline 2 years & 2 & 4.3 \\
\hline 1 year & 3 & 6.4 \\
\hline \multicolumn{3}{|l|}{ Days spent playing Pokémon Go in a week } \\
\hline 1-2 days & 5 & 10.6 \\
\hline 3-5 days & 9 & 19.1 \\
\hline 6-7 days & 33 & 70.2 \\
\hline \multicolumn{3}{|l|}{ Duration spent playing Pokémon Go in a day } \\
\hline Less than 1 hour & 12 & 25.5 \\
\hline 1-4 hours & 28 & 59.6 \\
\hline $5-8$ hours & 5 & 10.6 \\
\hline $9-12$ hours & 0 & 0 \\
\hline More than 12 hours & 2 & 4.3 \\
\hline
\end{tabular}

\subsection{Level of physical activity based on the Global Physical Activity Questionnaire (GPAQ)}

Pokémon Go players spent a median (IQR) of 540 (300-1200) minutes/week being physically active and a median (IQR) of 2412 (1200-4800) MET-minutes/week. 0 (0-180.0) minutes/week were spent on the moderate intensity of work that involves brisk walking.

The median time spent walking or cycling to travel to from places was $210.00(0-420.0)$ minutes/week.
A median of 60 (0-240.00) minutes/week was spent on vigorous recreational activity whereas $60(0-240.00)$ minutes/week were spent on moderate intensity recreational activities. The median time spent sedentary was 300.0 (240.0-480.0) minutes/day. Among the 47 players, $40.4 \%$ were having a high level of physical activity, $27.7 \%$ were having a moderate level of physical activity and the remaining $31.9 \%$ were categorized as low in physical activity level. Table 2 represents the mean and standard deviation of the GPAQ variables and Table 3 represents the level of physical activity among the players. 
Table 2 Mean and Standard deviation of Variables of GPAQ

\begin{tabular}{|l|l|}
\hline \multicolumn{1}{|c|}{ Variables in GPAQ } & \multicolumn{1}{|c|}{ Median (IQR) } \\
\hline Total time spent on moderate intensity during work per week (minutes) & $0(0-180.0)$ \\
\hline Total time spent walking/cycling per week for travel (minutes) & $210.00(0-420.0)$ \\
\hline Total time spent on vigorous recreational physical activity per week (minutes) & $60(0-240.00)$ \\
\hline Total time spent on moderate recreational physical activity per week (minutes) & $60.0(0-240.00)$ \\
\hline Total time spent sedentary per day (minutes) & $300.0(240.0-480.0)$ \\
\hline Total PA in minutes/week & $540.00(300-1200)$ \\
\hline Total MET-minutes/week & $2412.00(1200-4800)$ \\
\hline
\end{tabular}

\section{IQR- Interquartile ranges}

Table 3 Level of Physical Activity

\begin{tabular}{|l|c|c|}
\hline $\begin{array}{l}\text { Level of physical } \\
\text { activity }\end{array}$ & $\begin{array}{c}\text { Number } \\
(\mathrm{n})\end{array}$ & $\begin{array}{c}\text { Percentage } \\
(\%)\end{array}$ \\
\hline Low & 15 & 31.9 \\
\hline Moderate & 13 & 27.7 \\
\hline High & 19 & 40.4 \\
\hline
\end{tabular}

\subsection{Association between playing Pokémon Go and physical activity}

Based on the cross-tabulation, those who played Pokémon Go for 6-7 days have shown to have High level of physical activity compared to those who played for only 1- 2 days (Table 4). Nevertheless, in chisquare test analysis, a p-value of 0.14 was obtained and the null hypothesis could not reject. Hence, there was no significant association between days spent playing Pokémon Go and level of physical activity among players of Pokémon Go in Malaysia, $\chi 2(4, \mathrm{~N}=47)=6.931$, p $=.140$. There was also no association between hours spent playing Pokémon Go and physical activity, $\chi 2(6, \mathrm{~N}=47)=5.218, \mathrm{p}=.516$. Besides, no association between daily hours spent playing Pokémon Go and daily sedentary time, $\chi^{2}(8, \mathrm{~N}=47)=9.746, \mathrm{p}=.283$ were found.

Table 4 Association between days in a week playing Pokémon go and the level of physical activity

\begin{tabular}{|c|c|c|c|c|c|}
\hline & \multicolumn{3}{|c|}{ Level of Physical Activity } & \multirow[b]{2}{*}{ Total } \\
\hline & & Low & Moderate & High & \\
\hline \multirow{3}{*}{$\begin{array}{l}\text { Average of playing Pokémon } \\
\text { Go (Days/Week) }\end{array}$} & 1-2 days & 2 & 3 & 0 & 5 \\
\hline & 3-5 days & 2 & 4 & 3 & 9 \\
\hline & 6-7 days & 11 & 6 & 16 & 33 \\
\hline \multicolumn{2}{|r|}{ Total } & 15 & 13 & 19 & 47 \\
\hline
\end{tabular}

\section{Discussion}

The result of the current study reported that the time spent playing Pokémon Go was not associated with the players' level of physical activity or sedentary time. Nevertheless, based on the mean, those who played the game 1-2 days/ week showed a lack of involvement in high physical activity levels and leaned towards the moderate level of physical activity. On the contrary, those who played more frequently (6-7 days/week) were more involved in a high level of of physical activity compared to those who played 1-2 days/week Moreover, the number of players involved in high physical activity levels increased as the frequency of gameplay increased. The majority of the subjects played Pokémon Go 1-4 hours/day and the players had higher physical activity levels compared to those who played less than an hour/day. From this, there is a probability that those who played Pokémon Go more frequently tend to have a higher physical activity level but it is not associated with time spent gaming. Previous studies have reported that the main motive behind playing Pokémon Go is the players being Pokemon and game enthusiasts, followed by the motive of "staying active/walk more" (Marquet et al., 2017).

\section{Journal of Experimental Biology and Agricultural Sciences} http://www.jebas.org 
Therefore, there may be the possibility of other factors that might influence the increased level of physical activity among those who played Pokémon Go frequently. The small sample size of this study may also be a factorlimiting the statistical power and significance of the result.

Further, the findings of the current study were also similar to the previous study findings that stated the effects of Pokémon Go in motivating the physical activity levels lacks sustainability over some time (Althoff et al., 2016; Howe et al., 2016; Wattanapisit et al., 2018; $\mathrm{Ni}$ et al., 2019). Besides, another study conducted on the impact of Pokémon Go reported the effect didn't sustain beyond the first week (Ni et al., 2019) while another study discovered the effect only sustained for the first 30 days after the game is released (Althoff et al., 2016). Although, there is a significant increase in daily walking steps after playing Pokémon Go but the effect declines and stops at the 6th week post-game installation (Howe et al., 2016).

Thus, the current study was conducted approximately 3 years after the game was released and results showed there is no association between playing time spent playing Pokémon Go and physical activity. Based on the findings from the previous study, this could be possibly due to a lack of motivation and sustainability in playing the game in the long run (Althoff et al., 2016; Howe et al., 2016; Ni et al., 2019).

The results of this study were also comparable to the results of another correlation study that conducted among medical student in Thailand as there was no significant correlation between time spent playing Pokémon Go and the energy expenditure or sedentary behavior throughout their 3-month study period (Wattanapisit et al., 2018).

The limitation of the current study is the small sample size due to more than half of the players were excluded to minimize the influence of confounding variables. Secondly, self-administered questionnaire may be unreliable due to potential recall bias and reporting bias. Future study may involve a larger sample size and adopt devices such as accelerometers, pedometers, or other related health tracking applications to further provide greater insights on the virtual augmented game with a more precise, reliable physical activity measurement.

\section{Conclusion}

The current study revealed time spent playing Pokémon Go was not associated with the level of physical activity. Although this study showed there is a lack of association, the higher physical activity level is probable among frequent Pokémon players as it can be observed from the data those who spent more days playing Pokémon Go tend to have a higher level of physical activity. In contrary to the conservative approach of physical activity promotion such as awareness campaigns or health talks, incorporating technology and gaming enthusiasm may be more efficacious in motivating people to be physically engaging.
Integrating location-based AR games into fitness programs can be tempting to certain populations and an opportunity to foster a fun, active, and healthy lifestyle.

\section{References}

Althoff T, White RW, Horvitz E (2016) Influence of Pokémon Go on Physical Activity: Study and Implications. Journal of Medical Internet Research 18: 12.

Carlson KJ, Gagnon DJ (2017) Augmented Reality Integrated Simulation Education in Health Care. Clinical Simulation in Nursing 12(4): 123-127.

Herrmann SD, Heumann K, Ananian, Der C, Ainsworth BE (2013) Validity and Reliability of the Global Physical Activity Questionnaire (GPAQ). Measurement in Physical Education and Exercise Science 17(3): 221-235.

Howe KB, Suharlim C, Ueda P, Howe D, Kawachi I, Rimm EB (2016) Gotta catch'em all! Pokémon GO and physical activity among young adults: difference in differences study. Bmj 355(i6270). doi: https://doi.org/10.1136/bmj.i6270.

Leavy JE, Bull FC, Rosenberg M, Bauman A (2011) Physical activity mass media campaigns and their evaluation: A systematic review of the literature 2003-2010. Health Education Research 26(6): 10601085 .

Marquet O, Alberico C, Adlakha D, Hipp JA (2017) Examining Motivations to Play Pokémon GO and Their Influence on Perceived Outcomes and Physical Activity. JMIR Serious Games 5(4): e21.

Mum SJ, Ali L, Barnett A, Merom D (2017) Validity of the global physical activity questionnaire (GPAQ) in Bangladesh. BMC Public Health 17(1): 650. https://doi.org/10.1186/s12889-017-4666-0.

Ni MY, Hui RWH, Li TK, Tam AHM, Choy LLY, Ma KKW, Cheung F, Leung GM (2019) Augmented Reality Games as a New Class of Physical Activity Interventions? The Impact of Pokémon Go Use and Gaming Intensity on Physical Activity Games for Health Journal 8(1): 1-6. DOI: 10.1089/g4h.2017.0181.

Wattanapisit A, Saengow U, Ng CJ, Thanamee S, Kaewruang N (2018) Gaming behaviour with Pokémon GO and physical activity: A preliminary study with medical students in Thailand. PLoS One 2018 Jun 29;13(6):e0199813. doi: 10.1371/journal.pone.0199813.

World Health Organization (2018) Prevalence of insufficient physical activity among adults. WHO. Available at https://apps.who.int/gho/data/node.main.A893?lang=en access on 29th April 2020.

World Health Organization (2020) Physical Activity. WHO. Available at http://www.who.int/news-room/factsheets/detail/physical-activity access on 29th April 2020.

Zulkepli Z, Zakiah Moh N, Farah Moha N, Aishah Han S, Md. Zin N (2019) Relationship Between Physical Activity Level and Cardiovascular Risk Factors among Teachers. Asian Journal of Epidemiology 12(1): 1-8. 